\title{
Acute caffeine ingestion reduces insulin sensitivity in healthy subjects: a systematic review and meta-analysis
}

\author{
Xiuqin Shi ${ }^{\dagger}$, Wenhua Xue ${ }^{\dagger}$, Shuhong Liang, Jie Zhao ${ }^{*}$ and Xiaojian Zhang ${ }^{*}$ (D)
}

\begin{abstract}
Background: According to previous meta-analyses, coffee consumption reduces the risk of type 2 diabetes mellitus. However, the underlying mechanism remains unknown. Whether caffeine, the key ingredient in coffee, has a beneficial effect on the glycemic homeostasis and the anti-diabetic effect is particularly controversial. The aim of this study was to summarize the effect of acute caffeine ingestion on insulin sensitivity in healthy men.

Methods: A comprehensive literature search for papers published before April 2016 was conducted in EMBASE, PubMed, and Cochrane Library databases. Randomized controlled trials (RCTs) that investigated the effect of caffeine on insulin sensitivity in healthy humans without diabetes were included. A random effects meta-analysis was conducted using Review Manager 5.3.

Results: The search yielded 7 RCTs in which caffeine intake was the single variant. Compared with placebo, caffeine intake significantly decreased the insulin sensitivity index, with a standardized mean difference of -2.06 (95\% confidence interval -2.67 to $-1.44, I^{2}=49 \%$, $P$ for heterogeneity $=0.06$ ).

Conclusion: Acute caffeine ingestion reduces insulin sensitivity in healthy subjects. Thus, in the short term, caffeine might shift glycemic homeostasis toward hyperglycemia. Long-term trials investigating the role of caffeine in the anti-diabetic effect of coffee are needed.
\end{abstract}

Keywords: Caffeine, Insulin sensitivity, Diabetes, Risk factor

\section{Introduction}

The worldwide prevalence of type II diabetes has doubled in the previous two decades; this, in combination with the high disability and mortality rates has contributed to the serious effects of type II diabetes on human health [1]. A systematic analysis of health examination surveys and epidemiological studies estimated that the overall agestandardized incidence of diabetes was approximately 9.2\% for women and $9.8 \%$ for men [2]. Prevention of diabetes through the adoption of healthy dietary habits is particularly important for the effective management of hyperglycemia [3, 4].

Coffee is one of the most widely consumed beverages globally. Different amounts of coffee are habitually

\footnotetext{
* Correspondence: hnmuzj@163.com; xiaojianzhang2016@163.com ${ }^{\dagger}$ Equal contributors

Department of Pharmacy, The First Affiliated Hospital of Zhengzhou University, No. 43 Daxue Road, 450052 Zhengzhou, People's Republic of China
}

(c) The Author(s). 2016 Open Access This article is distributed under the terms of the Creative Commons Attribution 4.0 International License (http://creativecommons.org/licenses/by/4.0/), which permits unrestricted use, distribution, and reproduction in any medium, provided you give appropriate credit to the original author(s) and the source, provide a link to the Creative Commons license, and indicate if changes were made. The Creative Commons Public Domain Dedication waiver (http://creativecommons.org/publicdomain/zero/1.0/) applies to the data made available in this article, unless otherwise stated.

consumed to different countries or by people of different races; residents of the Netherlands and Finland are among the largest coffee drinkers, and Caucasians tend to consume more coffee than other races. Evidence is accumulating that habitual coffee consumption is linked to a reduced incidence of type II diabetes [5], and epidemiological studies conducted with people of different races have shown that coffee consumption is inversely correlated with the incidence of type II diabetes [6-16]. Importantly, higher consumption of all coffee products, caffeinated coffee, and decaffeinated coffee was associated with a lower risk of total mortality $[17,18]$.

Various mechanisms have been proposed regarding the protective effect of long-term coffee consumption against type II diabetes. Kemfp et al. reported that coffee consumption might have beneficial effects on subclinical inflammation and high-density lipoprotein cholesterol [19]. Kagami et al. showed that caffeine protects pancreatic beta 
cells against streptozocin toxicity [20]. Nevertheless, whether caffeine alone influences glycemic control, which is closely linked with diabetes-related micro- or macrovascular complications [21], remains unknown; this knowledge would provide insight into the role of caffeine in the putative relationship between coffee consumption and the risk of diabetes.

Caffeine, a mildly psycho-active chemical, is one of the most commonly consumed "drugs", with an average daily individual intake of approximately $300 \mathrm{mg}$ from dietary sources such as coffee, tea, soft drinks, chocolate, and energy drinks, among which coffee is the predominant source. Caffeine is one of the main components in coffee and is also used as an additive in more than $60 \%$ of available soft drinks [22]. Tea and other beverages that contain caffeine also reportedly protect against type II diabetes [23]. However, the underlying mechanism remains unclear, and the results of bedside and bench-based research are controversial $[19,24,25]$. Because type II diabetes is characterized by impaired insulin sensitivity, caffeine might play an important role in the protective effect of coffee against type II diabetes.

The current meta-analysis aimed to investigate the effect of caffeine alone on insulin sensitivity in healthy subjects. Whitehead et al. conducted a systematic review of randomized controlled trials (RCTs) of the effects of caffeine on glycemic control in people with diabetes mellitus [26]. However, the implications of the results might be limited, because the beneficial effect of coffee consumption for diabetes is supposedly more preventive than healing. Hence, data from healthy subjects are needed to investigate the protective effect of coffee against diabetes. Ding et al. conducted a systematic review of the association between caffeinated/decaffeinated coffee consumption and the risk of type II diabetes [18]. Similarly, Jiang et al. conducted a meta-analysis of prospective studies of the relationship between coffee/caffeine intake and the incidence of type II diabetes [17]. There is some discrepancy between these reviews regarding the effect of caffeine on diabetes prevalence. Because very few systematic reviews and meta-analyses have been conducted for RCTs on the association between caffeine alone and glycemic control in healthy subjects, the current meta-analysis could be significant for clarifying the inverse association between coffee consumption and type II diabetes.

\section{Methods}

\section{Search strategy}

The PubMed (1960 to April 2016; http://www.ncbi.nlm. nih.gov/pubmed/), EMBASE (1980 to April 2016; http:// www.embase.com/), and Cochrane Library (1985 to April 2016; http://www.cochrane.org/) databases were searched for RCTs that examined the effects of caffeine on insulin sensitivity in healthy humans. The following key words in the title/abstract were used: caffeine and glucose, glycemic control, insulin, or insulin sensitivity. The search was restricted to human clinical trials. In addition, the reference lists from selected reports were reviewed for further relevant studies. The systematic review was planned, conducted, and reported according to the PRISMA statement [27]. The review protocol was registered in the PROSPERO International Prospective Register of Systematic Reviews (CRD42016041224).

\section{Study selection}

The following criteria were used for study selection: 1) subjects consumed a caffeine-containing beverage before $\geq 2$-week washout during which no caffeine-containing products were consumed; 2 ) the study was an RCT with a parallel or crossover design conducted with healthy humans; 3) insulin sensitivity was calculated using standard deviations; 4) the only variant between the experimental and control groups was caffeine administration. The quality of the selected studies, regarding the risk of bias, was assessed using the computer program Review Manager (RevMan), Version 5.3 (The Nordic Cochrane Centre, The Cochrane Collaboration, Copenhagen).

Of the 366 studies identified in the initial search, the first review excluded 101 publications for not being relevant or a duplicate study, the second review excluded 247 publications because they did not describe human clinical trials, and the third review excluded 11 publications that did not include appropriate insulin sensitivity data. Therefore, 7 studies involving 70 participants were included (Fig. 1). The selected placebo was reviewed to assure that caffeine intake was the only variant. One study by Greenberg et al. [28] used two pairs of treatments: caffeine vs. placebo and caffeinated coffee vs. decaffeinated coffee. Only data from the latter pair were included because coffee consumption occurs more frequently than administration of pure caffeine in daily life.

\section{Data extraction}

Study features, including authors \& publication year, sample size (male: female), study design, and other relevant information were collected, in addition to the insulin sensitivity index (Table 1).

\section{Statistical analysis}

The current meta-analysis was performed using the computer program RevMan 5.3. Copenhagen. Heterogeneity between trial results was tested using a standard $\chi^{2}$ test. The $\mathrm{I}^{2}$ parameter was used to quantify any inconsistency, and $\mathrm{I}^{2}>50 \%$ was considered to represent substantial heterogeneity [29]. Because of the different methodologies adopted by individual researchers, a random-effects model was used to assess the standardized mean differences (SMD) and 95\% confidence intervals (CIs) in insulin 


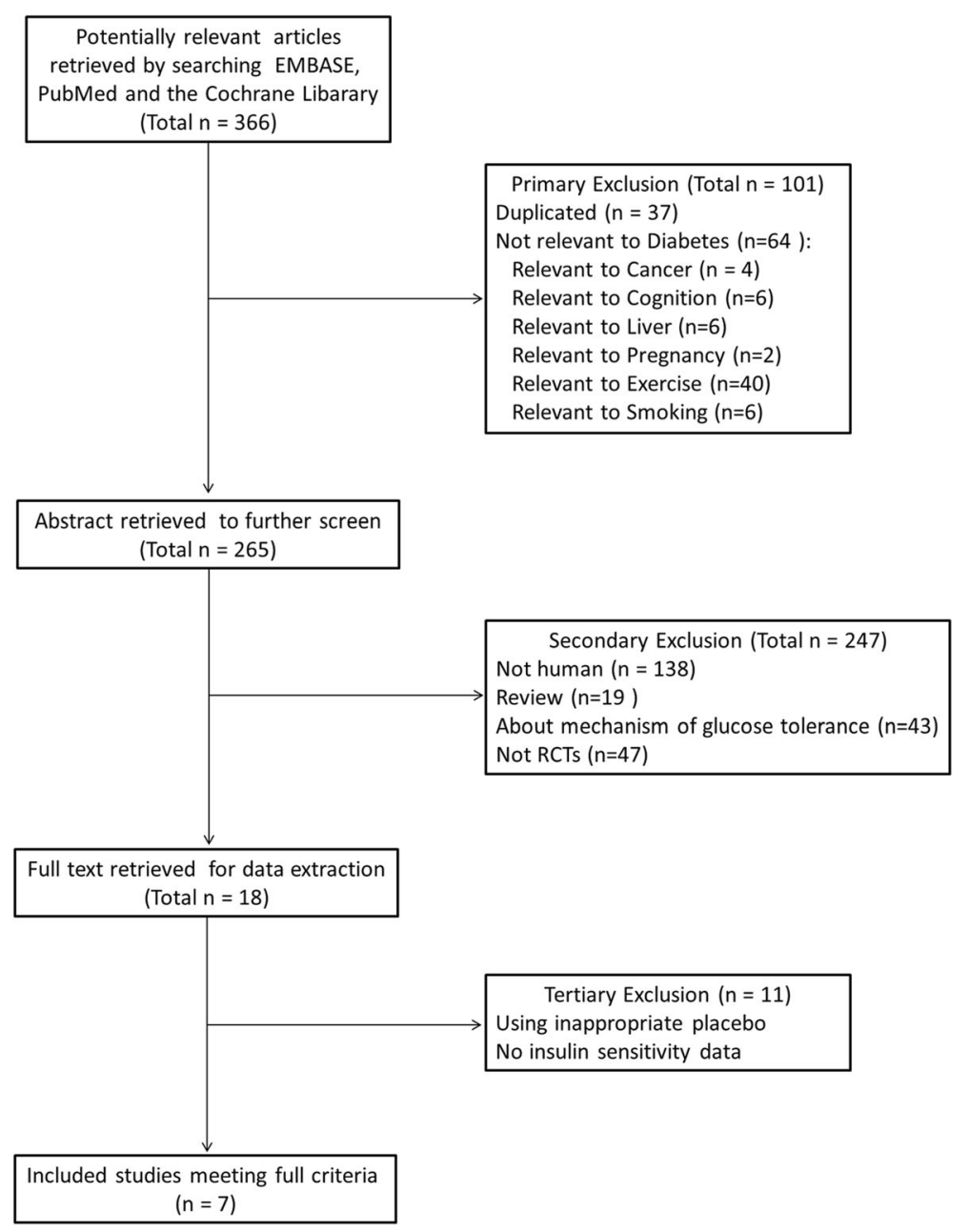

Fig. 1 Selection process of the identified articles

sensitivity. Forest plots were generated to illustrate the study-specific effect sizes and a 95\% CIs. Data extraction was independently conducted by the two co-first authors, with disagreements resolved by consensus.

\section{Results}

\section{Study characteristics}

The trial characteristics are shown in Table 1. The samples varied in size from 7 to 12 subjects. All the studies were of a single- or double-blind, randomized crossover design. Six of the seven trials [28, 30-34] included male subjects, and the sample in the remaining trial [35] was $50 \%$ men. All of the subjects had no history of diabetes or other metabolic diseases. All of the publications, except those by Petrie et al. [31] and Thong et al. [30], mentioned that the subjects were non-smokers. The subjects in 6 studies [28, 30, 32-35] were lean $\left(B M I \leq 25 \mathrm{~kg} / \mathrm{m}^{2}\right)$. The remaining trial conducted by Petrie et al. [31] examined the effects of caffeine ingestion and nutrition/exercise intervention in obese subjects (BMI $\left.34.0 \pm 1.0 \mathrm{~kg} / \mathrm{m}^{2}\right)$. All of the trials used a washout time of $\geq 48 \mathrm{~h}$. The most commonly used caffeine dose was $5 \mathrm{mg}$ caffeine $/ \mathrm{kg}$ body weight [30, 31, 33, 34], while Battram et al. [32] used $4.45 \mathrm{mg} / \mathrm{kg}$, Greenberg et al. [28] used $6 \mathrm{mg} / \mathrm{kg}$ and Keijzer used $3 \mathrm{mg} / \mathrm{kg}$.

\section{Data quality and risk of bias}

All of the included studies used a randomized, crossover design, reducing selection bias. However, the studies did not describe allocation concealment. In the study by Greenberg et al., the researchers were blinded to the participants' group. Because the researchers assigning the tested beverages were different from those who collected and analyzed the outcome data, the blinding of participants and personnel was rated unclear in relation to performance bias (Fig. 2a and b). In contrast, the principle researchers were blinded to all of the experimental treatments, but the subjects were not blinded to the 


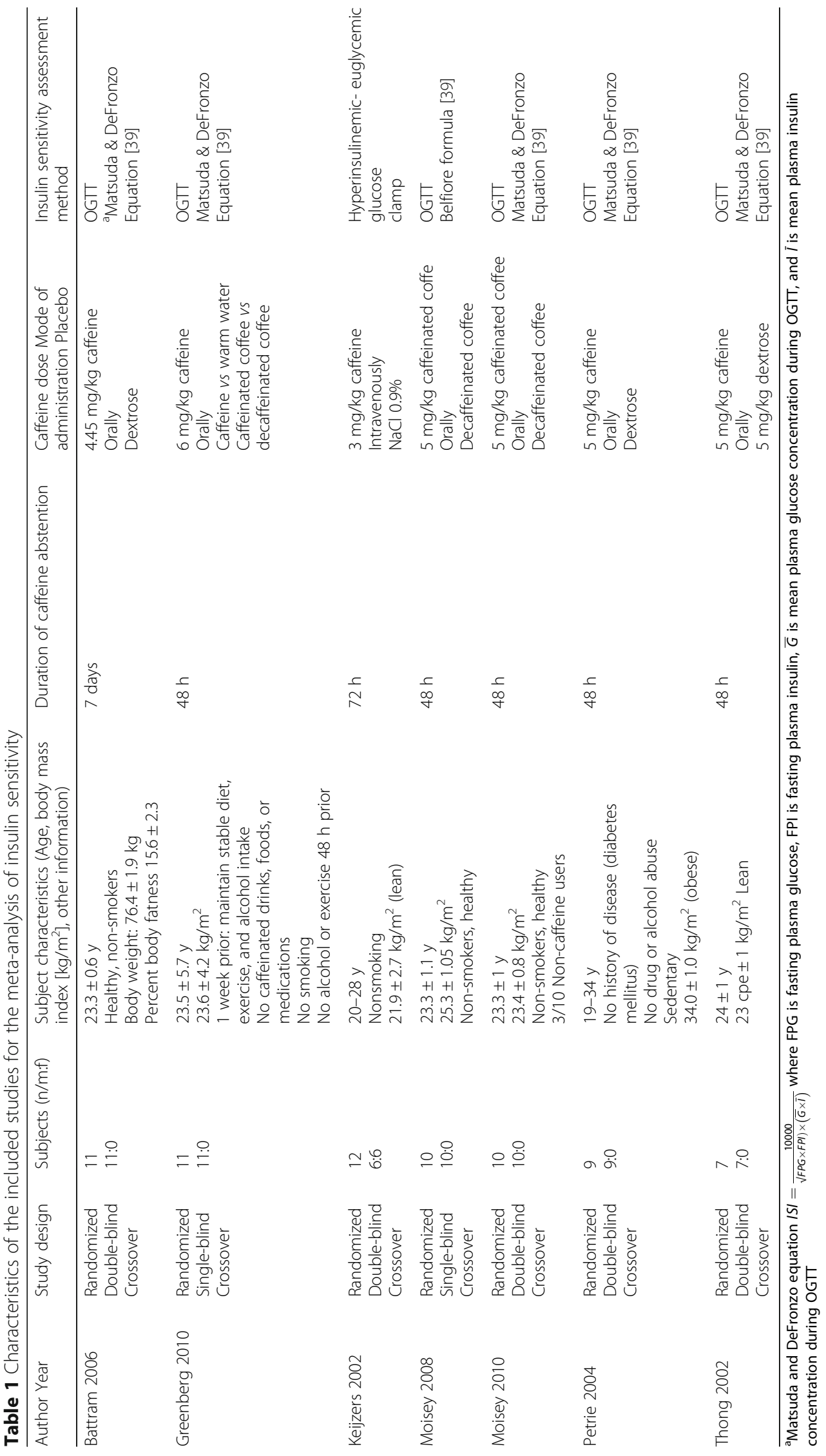




\section{a}

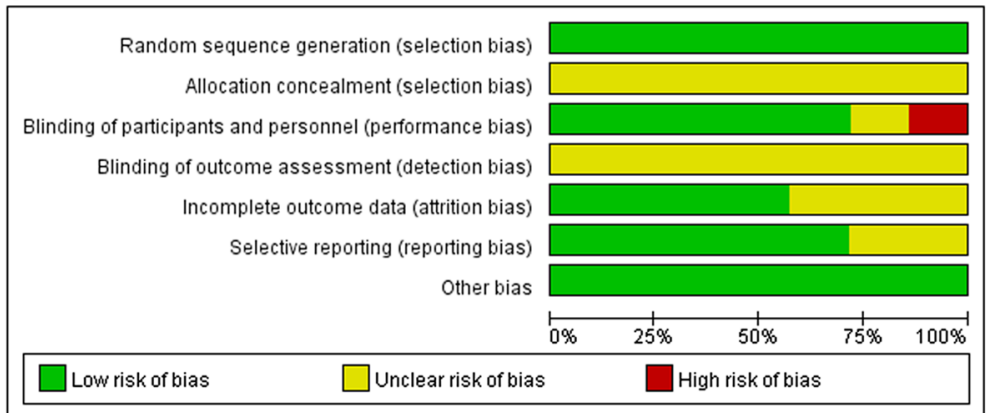

b

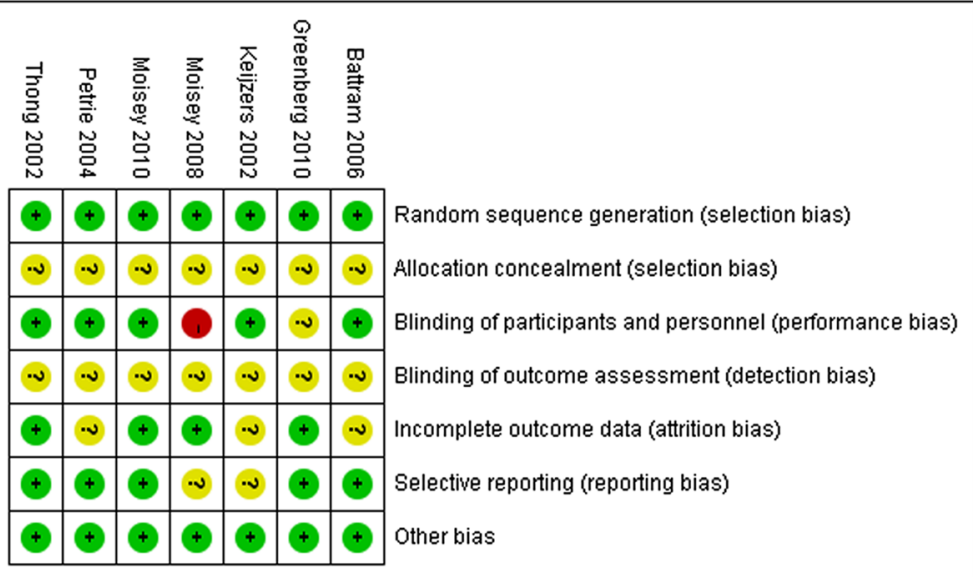

Fig. 2 Risk of bias assessment tool: (a) risk of bias graph; (b) risk of bias summary. Across trials, information is either from trials at a low risk of bias (green), at an unclear risk of bias (yellow), or at a high risk of bias (red)

cereal treatment in the study conducted by Moisey et al. [33]. Therefore, the knowledge that they were consuming cereal with a low glycemic index could have resulted in a substantial placebo effect; as a result, the risk of performance bias was rated as high. There were no specific statements about the blinding of the outcome assessment, resulting in unclear risk of detection bias. The measured outcomes in each included study were determined in the trial planning stage, and all but 2 reported all the pre- designed measurements, resulting in no reporting bias. No other bias was detected in the 7 studies.

\section{Caffeine consumption and insulin sensitivity in healthy subjects}

Figure 3 demonstrates the effect of caffeine consumption on insulin sensitivity in healthy subjects, as determined in the meta-analysis $[28,30-36]$. The included studies adopted two different strategies to determine the insulin

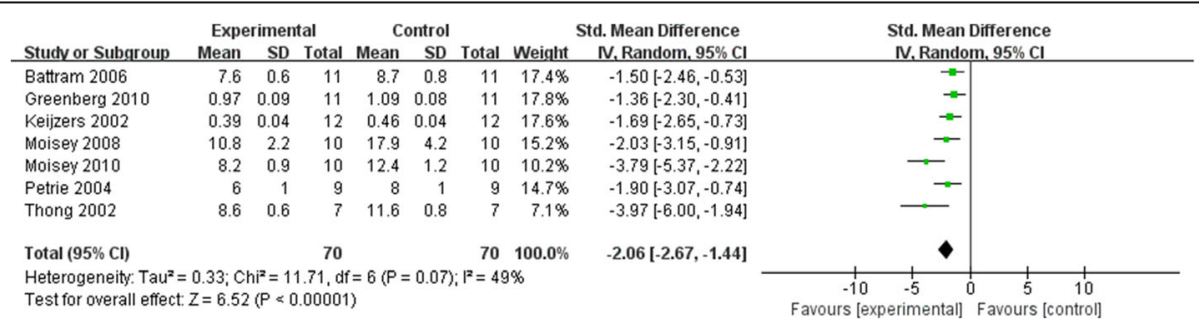

Fig. 3 Forest plot showing the pooled standardized mean difference (SMD) and 95\% confidence interval (CI) for insulin sensitivity for 7 randomized controlled trials. For each study of caffeine, the shaded square represents the point estimate of the intervention effect. The horizontal line joins the lower and upper limits of the $95 \% \mathrm{Cl}$ of these effects. The area of the shaded square reflects the relative weight of the study in the respective meta-analysis. The diamond at the bottom of the graph represents the pooled SMD with the $95 \% \mathrm{Cl}$ for the seven trials. Experimental: caffeine group; Control: control group; $I^{2}$ : Inconsistency 
sensitivity index: a hyperinsulinemic-euglycemic glucose clamp and/or the Matsuda and DeFronzo equation [37] after an oral glucose tolerance test (OGTT). Keijzers et al. [35] was the first to use a hyperinsulinemic-euglycemic glucose clamp to calculate the insulin sensitivity in 12 non-smoking, lean, normotensive, healthy volunteers. Owing to the different methodologies, we used the SMD to measure the effect, inverse variance as the statistical method, and random effects as the analytic model.

All trials consistently reported a reduction in insulin sensitivity with caffeine consumption. Compared with placebo, caffeine intake significantly decreased the insulin sensitivity index (SMD $-2.06,95 \% \mathrm{CI}-2.67$ to -1.44 , $\mathrm{I}^{2}=49 \%, P$ for heterogeneity $\left.=0.07\right)$. The trial performed by Petrie et al. [31] generated two sets of data for the effect of caffeine ingestion: before and after a nutrition/ exercise intervention. The intervention significantly decreased body weight and percentage body fat. Subsequently, the insulin sensitivity index markedly increased from $4 \pm 1$ (caffeine) and $5 \pm 1$ (placebo) to $6 \pm 1$ (caffeine) and $8 \pm 1$ (placebo). We included the data after the nutrition and exercise intervention because the heterogeneity was lower, as compared with the other included studies.

The epidemiological evidence for an inverse association between coffee and type II diabetes is strong, while evidence is accumulating that acute caffeine intake might impair glucose metabolism. Therefore, the effect of decaffeinated coffee on glycemic control was tested by many scientists. Greenberg et al. [28] reported acutely impaired glucose metabolism by decaffeinated coffee in healthy young men. However, Battram et al. [32] found an acute enhancement of glucose metabolism by ground decaffeinated coffee, while Johnston et al. [38], Tom [39], and Van Dijk et al. [40] found no acute effect on glucose metabolism by instant decaffeinated coffee.

Elevated glucose and insulin response after caffeine intake A 2-h OGTT is commonly used by researchers to investigate glucose homeostasis. During the screening of the literature, we found another set of 7 studies $[31-33,36,38,41,42]$ that explore the effect of caffeine on glucose modulation, reporting the area under the curve (AUC) for glucose and insulin. Pizzol et al. [42] tested the effects of $200 \mathrm{mg}$ oral caffeine on glucose tolerance; during a 4-h OGTT, the glycemic curve was normal in both the caffeine and placebo groups until the second hour, but shifted towards the right in the caffeine group in the 2nd, 3rd, and 4th hours, compared with placebo. The AUC was separated into two parts: initial phase ( $\leq 2$ nd hour) and terminal phase (3rd and 4th hours). Unfortunately, the heterogeneity of these studies was too large to effectively perform a meta-analysis $\left(\mathrm{I}^{2}=87 \%, P<0.001\right)$; however, all of the studies consistently reported elevated AUCs for both glucose and insulin.

\section{Discussion}

In the current meta-analysis, acute administration of caffeine reduced insulin sensitivity. Therefore, the inverse association between coffee and diabetes was not attributed to enhanced glucose control.

The global difference in caffeine intake could stem from multiple reasons, including different dietary habits. Residents of Western countries tend to drink more coffee, while residents of Eastern countries tend to drink more tea. Genetic reasons could also contribute; in a recent publication in Scientific Reports, a team of researchers reported that participants in Italy and the Netherlands with the genetic variant PDSS2 tended to drink one fewer cup of coffee per day than those without the variant [43]. Further analysis revealed PDSS2 gene expression appears to inhibit the body's ability to break down caffeine [43]. Therefore, people with this variant would require less coffee for the same caffeine effect because the caffeine would be available in their system for a longer time.

Caffeine (1, 3, 7-trimethylxanthine) is a derivative of methylxanthine, a potentially antagonizing adenosine receptor. Data from animal models or in-vitro studies indicate that methylxanthines are involved in insulinmediated glucose metabolism in adipose and muscle tissue $[44,45]$, implying a close link between caffeine and glycemic control. However, caffeine might also regulate glucose metabolism by reducing the intracellular energy status in an insulin-independent manner [46].

The current meta-analysis could be of some significance for clarifying the relationship between caffeine consumption and diabetes. In a systematic review, Ding et al. compared the trends of the association between caffeinated/ decaffeinated coffee and the risk of type II diabetes. The authors reported a protective effect of decaffeinated coffee against diabetes, indicating that components of coffee other than caffeine are responsible for the putative beneficial effect. However, without data from those who consume pure caffeine, the aforementioned conclusion could be without basis. In contrast, in the meta-analysis by Jiang et al., which explored the association between coffee/ caffeine intake and type II diabetes incidence, the doseresponse data suggested that incremental caffeine intake had a stronger beneficial effect for type II diabetes than coffee intake, and caffeine intake provided greater protection than decaffeinated coffee intake. The results implied an indispensable role of caffeine in the protective effect against diabetes. The current meta-analysis demonstrated that acute caffeine ingestion was associated with reduced insulin sensitivity, implying that the long-term benefit of caffeine intake could be attributed to better management of calorie intake in coffee drinkers.

This review has some limitations. Restricted by the selection strategy, the selected trials all had a relatively small sample size. Nevertheless, the current results are supported 
by plenty of indirect evidence. Thong et al. demonstrated that caffeine induces insulin-stimulated glucose uptake in human skeletal muscle [47]. In addition, the antagonistic effects of caffeine on insulin in vivo are reportedly mediated by elevated epinephrine levels [30]. Furthermore, chronic caffeine intake reverses aging-induced insulin resistance in rats [48], highlighting the beneficial effect of long-term caffeine intake. Hence, further long-term RCTs of caffeine intake are needed to elucidate the underlying mechanism of the inverse association between coffee consumption and type II diabetes.

The significance of caffeine in diabetes is noticeable in other areas. For patients with diabetes, it is vital to be aware of decreasing blood glucose levels, because a lack of awareness about hypoglycemia is dangerous. The study by Debrah et al. found that caffeine induces a sustained decrease in middle cerebral artery velocity and augments sympathoadrenal and symptomatic responses during moderate hypoglycemia, representing a potentially useful treatment for patients with diabetes that have difficulty recognizing the onset of hypoglycemia [49].

\section{Conclusions}

The current meta-analysis demonstrated that acute administration of caffeine attenuates insulin sensitivity in healthy subjects. It is imperative that additional evidence about the chronic effect of caffeine be collected to better understand the role of coffee in the development and prevention of type 2 diabetes.

\section{Acknowledgements}

All authors are salaried employees of The First Affiliated Hospital of Zhengzhou University. The current research was also supported by the National Natural Science Foundation of China (71673254).

\section{Funding}

This work was supported by the National Natural Science Foundation of China (71673254).

\section{Authors' contributions}

Prof. XZ was responsible for the principal design of the article, with the completion of other authors. Ms. XS and Ms. WX conducted the literature searching and meta-analysis. All the authors participated in the analysis and the interpretation of the data. Ms. SL and Prof. led and conducted the critical revision of the study, with the assistance of other authors. At last, Ms. XS and Ms. SL drafted and revised the manuscript with the participation of all the authors. Prof. JZ was responsible for the acquisition of the supporting foundation: the National Natural Science Foundation of China (71673254). Disagreements were resolved by consensus, all authors read and approved of the final manuscript.

\section{Competing interests}

The authors declare that they have no competing interests.

\section{Consent for publication}

Not applicable.

\section{Ethics approval and consent to participate}

Not applicable.

Received: 9 July 2016 Accepted: 25 November 2016 Published online: 28 December 2016

\section{References}

1. Sandu M-M, Protasiewicz DC, Firănescu AG, Lăcătuşu EC, Bîcu ML, Moța M. Data regarding the prevalence and incidence of diabetes mellitus and prediabetes. Rom J Diabetes Nutr Metab Dis. 2016:23:95-103.

2. Danaei G, Finucane MM, Lu Y, Singh GM, Cowan MJ, Paciorek CJ, Lin JK, Farzadfar F, Khang YH, Stevens GA, et al. National, regional, and global trends in fasting plasma glucose and diabetes prevalence since 1980: systematic analysis of health examination surveys and epidemiological studies with 370 country-years and 2.7 million participants. Lancet. 2011;378:31-40.

3. American Diabetes A. Evidence-based nutrition principles and recommendations for the treatment and prevention of diabetes and related complications. Diabetes Care. 2002;25:202-12.

4. Martinez-Gonzalez MA, de la Fuente-Arrillaga C, Nunez-Cordoba JM, Basterra-Gortari FJ, Beunza JJ, Vazquez Z, Benito S, Tortosa A, Bes-Rastrollo M. Adherence to mediterranean diet and risk of developing diabetes: prospective cohort study. BMJ. 2008;336:1348-51.

5. van Dam RM, Hu FB. Coffee consumption and risk of type 2 diabetes: a systematic review. JAMA. 2005;294:97-104.

6. van Dam RM, Feskens EJ. Coffee consumption and risk of type 2 diabetes mellitus. Lancet. 2002;360:1477-8.

7. Salazar-Martinez E, Willett WC, Ascherio A, Manson JE, Leitzmann MF, Stampfer MJ, Hu FB. Coffee consumption and risk for type 2 diabetes mellitus. Ann Intern Med. 2004;140:1-8.

8. van Dam RM, Willett WC, Manson JE, Hu FB. Coffee, caffeine, and risk of type 2 diabetes: a prospective cohort study in younger and middle-aged U.S. women. Diabetes Care. 2006;29:398-403.

9. Hjellvik V , Tverdal A, Strom H. Boiled coffee intake and subsequent risk for type 2 diabetes. Epidemiology. 2011;22:418-21.

10. Carlsson S, Hammar N, Grill V, Kaprio J. Coffee consumption and risk of type 2 diabetes in finnish twins. Int J Epidemiol. 2004;33:616-7.

11. Floegel A, Pischon T, Bergmann MM, Teucher B, Kaaks R, Boeing H. Coffee consumption and risk of chronic disease in the European prospective investigation into cancer and nutrition (EPIC)-Germany study. Am J Clin Nutr. 2012;95:901-8.

12. Iso H, Date C, Wakai K, Fukui M, Tamakoshi A, Group JS. The relationship between green tea and total caffeine intake and risk for self-reported type 2 diabetes among Japanese adults. Ann Intern Med. 2006;144:554-62.

13. Oba S, Nagata C, Nakamura K, Fujii K, Kawachi T, Takatsuka N, Shimizu H. Consumption of coffee, green tea, oolong tea, black tea, chocolate snacks and the caffeine content in relation to risk of diabetes in Japanese men and women. Br J Nutr. 2010;103:453-9.

14. Reunanen A, Heliovaara M, Aho K. Coffee consumption and risk of type 2 diabetes mellitus. Lancet. 2003;361:702-3. author reply 703.

15. Goto A, Song Y, Chen BH, Manson JE, Buring JE, Liu S. Coffee and caffeine consumption in relation to sex hormone-binding globulin and risk of type 2 diabetes in postmenopausal women. Diabetes. 2011;60:269-75.

16. Pereira MA, Parker ED, Folsom AR. Coffee consumption and risk of type 2 diabetes mellitus: an 11-year prospective study of 28812 postmenopausal women. Arch Intern Med. 2006;166:1311-6.

17. Jiang $X$, Zhang D, Jiang W. Coffee and caffeine intake and incidence of type 2 diabetes mellitus: a meta-analysis of prospective studies. Eur J Nutr. 2014;53:25-38.

18. Ding M, Bhupathiraju SN, Chen M, van Dam RM, Hu FB. Caffeinated and decaffeinated coffee consumption and risk of type 2 diabetes: a systematic review and a dose-response meta-analysis. Diabetes Care. 2014;37:569-86

19. Kempf K, Herder C, Erlund I, Kolb H, Martin S, Carstensen M, Koenig W, Sundvall J, Bidel S, Kuha S, Tuomilehto J. Effects of coffee consumption on subclinical inflammation and other risk factors for type 2 diabetes: a clinical trial. Am J Clin Nutr. 2010;91:950-7.

20. Kagami K, Morita H, Onda K, Hirano T, Oka K. Protective effect of caffeine on streptozotocin-induced beta-cell damage in rats. J Pharm Pharmacol. 2008;60:1161-5.

21. Saydah SH, Fradkin J, Cowie CC. Poor control of risk factors for vascular disease among adults with previously diagnosed diabetes. JAMA. 2004:291:335-42.

22. Keast RS, Riddell $\sqcup$. Caffeine as a flavor additive in soft-drinks. Appetite. 2007:49:255-9.

23. van Dieren $S$, Uiterwaal $C S$, van der Schouw $Y T$, van der AD, Boer JM, Spijkerman A, Grobbee DE, Beulens JW. Coffee and tea consumption and risk of type 2 diabetes. Diabetologia. 2009;52:2561-9. 
24. Olateju T, Begley J, Green DJ, Kerr D. Physiological and glycemic responses following acute ingestion of a popular functional drink in patients with type 1 diabetes. Can J Diabetes. 2015;39:78-82.

25. Lane JD, Hwang AL, Feinglos MN, Surwit RS. Exaggeration of postprandial hyperglycemia in patients with type 2 diabetes by administration of caffeine in coffee. Endocr Pract. 2007:13(3):239-43.

26. Whitehead $\mathrm{N}$, White $\mathrm{H}$. Systematic review of randomised controlled trials of the effects of caffeine or caffeinated drinks on blood glucose concentrations and insulin sensitivity in people with diabetes mellitus. J Hum Nutr Diet. 2013;26:111-25

27. Moher D, Liberati A, Tetzlaff J, Altman DG, Group P. Preferred reporting items for systematic reviews and meta-analyses: the PRISMA statement. Int J Surg. 2010;8:336-41.

28. Greenberg JA, Owen DR, Geliebter A. Decaffeinated coffee and glucose metabolism in young men. Diabetes Care. 2010;33:278-80.

29. Schwingshackl L, Hoffmann G. Long-term effects of low-fat diets either low or high in protein on cardiovascular and metabolic risk factors: a systematic review and meta-analysis. Nutr J. 2013;12:48

30. Thong FS, Graham TE. Caffeine-induced impairment of glucose tolerance is abolished by beta-adrenergic receptor blockade in humans. J Appl Physiol (1985). 2002;92:2347-52.

31. Petrie HJ, Chown SE, Belfie LM, Duncan AM, McLaren DH, Conquer JA, Graham TE. Caffeine ingestion increases the insulin response to an oralglucose-tolerance test in obese men before and after weight loss. Am J Clin Nutr. 2004;80:22-8.

32. Battram DS, Arthur R, Weekes A, Graham TE. The glucose intolerance induced by caffeinated coffee ingestion is less pronounced than that due to alkaloid caffeine in men. J Nutr. 2006;136:1276-80.

33. Moisey LL, Kacker S, Bickerton AC, Robinson LE, Graham TE. Caffeinated coffee consumption impairs blood glucose homeostasis in response to high and low glycemic index meals in healthy men. Am J Clin Nutr. 2008;87:1254-61.

34. Moisey LL, Robinson LE, Graham TE. Consumption of caffeinated coffee and a high carbohydrate meal affects postprandial metabolism of a subsequent oral glucose tolerance test in young, healthy males. Br J Nutr. 2010;103:833-41.

35. Keijzers GB, De Galan BE, Tack CJ, Smits P. Caffeine can decrease insulin sensitivity in humans. Diabetes Care. 2002;25:364-9.

36. Dekker MJ, Gusba JE, Robinson LE, Graham TE. Glucose homeostasis remains altered by acute caffeine ingestion following 2 weeks of daily caffeine consumption in previously non-caffeine-consuming males. $\mathrm{Br} J$ Nutr. 2007:98:556-62.

37. Matsuda M, DeFronzo RA. Insulin sensitivity indices obtained from oral glucose tolerance testing: comparison with the euglycemic insulin clamp. Diabetes Care. 1999;22:1462-70.

38. Johnston KL, Clifford MN, Morgan LM. Coffee acutely modifies gastrointestinal hormone secretion and glucose tolerance in humans: glycemic effects of chlorogenic acid and caffeine. Am J Clin Nutr. 2003;78:728-33.

39. Thom $E$. The effect of chlorogenic acid enriched coffee on glucose absorption in healthy volunteers and its effect on body mass when used long-term in overweight and obese people. J Int Med Res. 2007:35:900-8.

40. van Dijk AE, Olthof MR, Meeuse JC, Seebus E, Heine RJ, van Dam RM. Acute effects of decaffeinated coffee and the major coffee components chlorogenic acid and trigonelline on glucose tolerance. Diabetes Care. 2009;32:1023-5.

41. Graham TE, Sathasivam P, Rowland M, Marko N, Greer F, Battram D. Caffeine ingestion elevates plasma insulin response in humans during an oral glucose tolerance test. Can J Physiol Pharmacol. 2001;79(7):559-65.

42. Pizziol A, Tikhonoff V, Paleari CD, Russo E, Mazza A, Ginocchio G, Onesto C, Pavan L, Casiglia E, Pessina AC. Effects of caffeine on glucose tolerance: a placebo-controlled study. Eur J Clin Nutr. 1998;52:846-9.

43. Pirastu N, Kooyman M, Robino A, van $\operatorname{der}$ Spek A, Navarini L, Amin N Karssen LC, Van Duijn CM, Gasparini P. Non-additive genome-wide association scan reveals a new gene associated with habitual coffee consumption. Sci Rep. 2016;6:31590.

44. Dray C, Daviaud D, Guigne C, Valet P, Castan-Laurell I. Caffeine reduces TNFalpha up-regulation in human adipose tissue primary culture. J Physiol Biochem. 2007;63:329-36.

45. Tsuda S, Egawa T, Kitani K, Oshima R, Ma X, Hayashi T. Caffeine and contraction synergistically stimulate 5'-AMP-activated protein kinase and insulin-independent glucose transport in rat skeletal muscle. Physiol Rep. 2015;3.

46. Egawa T, Hamada T, Kameda N, Karaike K, Ma X, Masuda S, Iwanaka N, Hayashi T. Caffeine acutely activates 5'adenosine monophosphate-activated protein kinase and increases insulin-independent glucose transport in rat skeletal muscles. Metabolism. 2009;58:1609-17.

47. Thong FS, Derave W, Kiens B, Graham TE, Urso B, Wojtaszewski JF, Hansen BF, Richter EA. Caffeine-induced impairment of insulin action but not insulin signaling in human skeletal muscle is reduced by exercise. Diabetes. 2002;51:583-90.

48. Guarino MP, Ribeiro MJ, Sacramento JF, Conde SV. Chronic caffeine intake reverses age-induced insulin resistance in the rat: effect on skeletal muscle Glut4 transporters and AMPK activity. Age (Dordr). 2013;35:1755-65.

49. Debrah K, Sherwin RS, Murphy J, Kerr D. Effect of caffeine on recognition of and physiological responses to hypoglycaemia in insulin-dependent diabetes. Lancet. 1996;347:19-24.

\section{Submit your next manuscript to BioMed Central and we will help you at every step:}

- We accept pre-submission inquiries

- Our selector tool helps you to find the most relevant journal

- We provide round the clock customer support

- Convenient online submission

- Thorough peer review

- Inclusion in PubMed and all major indexing services

- Maximum visibility for your research

Submit your manuscript at www.biomedcentral.com/submit
) Biomed Central 